\title{
In Search of High-Performance Platinum(II) Phosphorescent Materials for the Fabrication of Red Electroluminescent Devices**
}

\author{
By Jakka Kavitha, Sheng-Yuan Chang, Yun Chi, * Jen-Kan Yu, Ya-Hui Hu, Pi-Tai Chou,* Shie-Ming Peng, \\ Gene-Hsiang Lee, Yu-Tai Tao,* Chin-Hsiung Chien, and Arthur J. Carty
}

The rational design and syntheses of $\mathrm{Pt}(\mathrm{iqdz})_{2}(\mathbf{1})$ and $\mathrm{Pt}(\mathrm{pydz})_{2}(\mathbf{2})$ bearing isoquinolinyl indazole (iqdz)H or pyridyl indazole (pydz) $\mathrm{H}$ groups on the coordinating ligands are reported. Single-crystal X-ray diffraction studies of $\mathbf{1}$ reveal a square planar geometry, in which two iqdz ligands adopt a trans-configuration. Short $\mathrm{N} \cdots \mathrm{H}$ contacts $(\sim 2.21 \AA)$ are detected between the orthohydrogen atom of isoquinoline and the adjacent $\mathrm{N}$ atom of the indazole fragment, making the overall molecular geometry analogous to that of the platinum(II) porphyrinato complexes. The lowest absorption bands for both complexes reveal strong state mixings between singlet and triplet (metal-to-ligand charge transfer and intra-ligand) manifolds. This, in combination with the introduction of a camphor-like structure to avoid the stacking effect, leads to phosphorescence with unprecedented brightness both in solution and in the solid state. Organic light-emitting diode (OLED) devices fabricated using $\mathbf{1}$ as a dopant emitter have been achieved in a multilayer configuration. The results constitute the first highly efficient $\mathrm{Pt}^{\mathrm{II}}$-based red OLED.

\section{Introduction}

Owing to their potential to harness the energies of both the singlet and triplet excitons after charge recombination, transition-metal-based phosphorescent materials have recently received considerable attention for fabricating organic lightemitting diodes (OLEDs). ${ }^{[1]}$ The main advantages are due to the heavy-atom-induced singlet-to-triplet intersystem crossing as well as the large enhancement of radiative decay rate from the resulting triplet manifolds. In this regard, numerous attempts have been made to exploit third-row transition metal complexes as dopant emitters for OLED fabrication, ${ }^{[2-4]}$ among which quite a few $\mathrm{Pt}^{\mathrm{II}},{ }^{2]} \mathrm{Os}^{\mathrm{II}},{ }^{[3]}$ and $\mathrm{Ir}^{\mathrm{III}[4]}$ complexes have been reported to exhibit highly efficient device performances. Despite these developments, attempts to further ex-

[*] Prof. Y. Chi, Prof. Y.-T. Tao, Dr. J. Kavitha, S.-Y. Chang, Department of Chemistry

National Tsing Hua University

Hsinchu 300, Taiwan (R.O.C.)

E-mail:ychi@mx.nthu.edu.tw

Prof. P.-T. Chou, J.-K. Yu, Y.-H. Hu, Prof. S.-M. Peng, G.-H. Lee

Department of Chemistry and Instrumentation Center

National Taiwan University

Taipei 106, Taiwan (R.O.C.)

E-mail: chop@ntu.edu.tw

Prof. Y.-T. Tao, C.-H. Chien

Institute of Chemistry, Academia Sinica

Taipei 115, Taiwan (R.O.C.)

E-mail: ytt@gate.sinica.edu.tw

Prof. A. J. Carty

Steacie Institute for Molecular Sciences

National Research Council

Ottowa, Ontario K1A 0R6 (Canada)

[**] We thank the National Science Council of Taiwan, for financial support (NSC 91-2119-M-002-016 and NSC 91-2113-M-007-006). pand the potential of the square planar $\mathrm{Pt}^{\mathrm{II}}$ complexes, in which the central metal ion possesses a higher atomic number than $\mathrm{Os}^{\mathrm{II}}$ and $\mathrm{Ir}^{\mathrm{III}}$, for efficient OLED applications has encountered many intrinsic obstacles. ${ }^{[4]}$ For example, the PtOEP (where $\mathrm{H}_{2} \mathrm{OEP}$ is octaethylporphyrin) type of emitter commonly has a ligand-based phosphorescence with lifetimes as long as 30-50 $\mu$ s, so that saturation of emissive sites and a rapid drop in device efficiency at high drive current is observed. Another factor contributing to the poor device efficiency is the planar molecular configuration of many $\mathrm{Pt}^{\mathrm{II}}$ complexes, which leads to stacking and the formation of aggregates ${ }^{[5]}$ or excimers. ${ }^{[6]}$ To realize the potential of $\mathrm{Pt}^{\mathrm{II}}$ materials for application in highefficiency OLEDs, the rational design of $\mathrm{Pt}^{\mathrm{II}}$ complexes aimed at the reduction of the phosphorescence radiative lifetime and the prevention of stacking behavior are critical. In this paper, we report the design and synthesis of a new series of emissive $\mathrm{Pt}^{\mathrm{II}}$ complexes, in which the associated ligand chromophores possess a bulky, rigid camphor-like architecture to effectively suppress the aggregation effect. Moreover, drastic reduction of the phosphorescence radiative lifetime to several microseconds has also been achieved due to the strong singlet-triplet state mixings. Consequently, highly efficient $\mathrm{Pt}^{\mathrm{II}}$ OLEDs operating at $610-630 \mathrm{~nm}$ have been successfully prepared for the first time, in which the dopant $\left(\mathrm{Pt}^{\mathrm{II}}\right.$ complex) concentration, owing to the reduced aggregation effect, can be substantially increased to maximize performance.

\section{Results and Discussion}

\subsection{Synthesis and Characterization}

As depicted in Scheme 1, the required camphor-derivatized chelating ligand was synthesized in two steps employing a direct condensation of ethyl 1-isoquinolinecarboxylate and $(1 R)-(+)$-camphor, followed by treatment with hydrazine hy- 


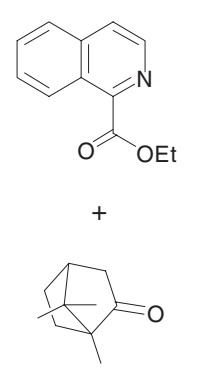

(iqdz) $\mathrm{H}$

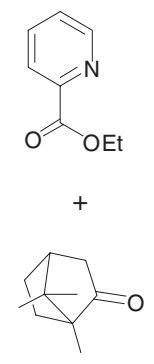

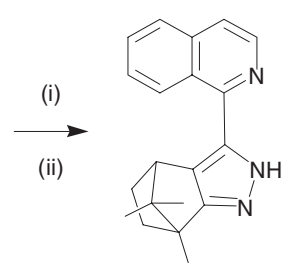

(iii)

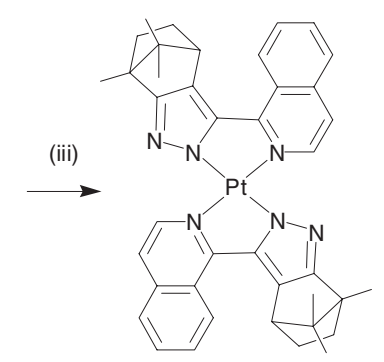

(1)

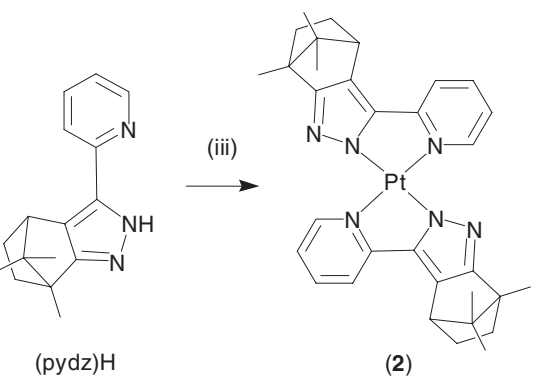

(2)

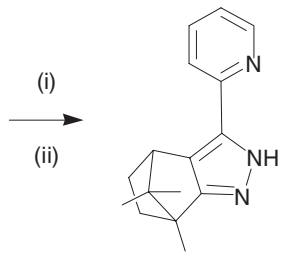

(pydz)H (i) $\mathrm{NaH}$, THF (ii) $\mathrm{N}_{2} \mathrm{H}_{4}$, EtOH, (iii) $\mathrm{K}_{2} \mathrm{PtCl}_{4}, 80^{\circ} \mathrm{C}, 16 \mathrm{~h}$.

Scheme 1. Syntheses of 1 and $\mathbf{2}$.

drate in refluxing ethanol to induce formation of the indazole skeleton. ${ }^{[7]}$ Subsequent treatment with $\mathrm{K}_{2} \mathrm{PtCl}_{4}$ in a mixture of water and ethanol gave a dark-red $\mathrm{Pt}$ complex denoted as $\mathrm{Pt}(\mathrm{iqdz})_{2}$ (1) in good yield. A similar method, but with ethyl 1-isoquinolinecarboxylate replaced by picolinate, yielded the yellowish green platinum complex $\mathrm{Pt}(\mathrm{pydz})_{2}(\mathbf{2})$. Both Pt complexes were highly soluble in organic solvents and have been characterized using various spectroscopic methods (see Experimental section). Their spectroscopic data are in good agreement with the expected square planar $\mathrm{Pt}^{\mathrm{II}}$ complexes coordinated with two indazole chelates. Complex 1 was further examined by single-crystal X-ray diffraction analysis to establish its molecular structure.

Figure 1 depicts the ORTEP diagram of $\mathbf{1}$, along with that of a second, symmetry-related molecule shown in pale gray. An overlap between the isoquinoline fragments of these two proximal complexes is clearly noted with a moderate interplanar spacing of $3.64 \AA$. All methyl-substituted bridges on the camphor moieties point in the same direction due to the selection of a chiral reagent, $(1 R)-(+)$-camphor, for the original ligand preparation. The Pt...Pt separation was calculated to be 6.857(7) $\AA$, which is much too long to expect any significant $\mathrm{Pt}-\mathrm{Pt}$ interaction such as those observed in dimers of cyclometalated $\mathrm{Pt}^{\mathrm{II}}$ complexes $(3.15-3.76 \AA) .{ }^{[8]}$ Moreover, the Pt atom is bonded to two chelating iqdz ligands in a trans-arrangement. The Pt- $\mathrm{N}_{\text {(inda) }}$ distances of 1.976 and $2.005 \AA$ in $\mathbf{1}$ are slightly shorter than the $\mathrm{Pt}-\mathrm{N}_{\text {(quin) }}$ dative bonds (2.011 and $2.047 \AA$ ), which are within the range reported for those of $[\operatorname{Pt}(\alpha$-diimine) $\mathrm{Cl}_{2}$ ] (1.992-2.015 $\AA$ ) and related complexes. ${ }^{[9]}$ Moreover, short $\mathrm{N} \cdots \mathrm{H}$ contacts $(\sim 2.21 \AA)$ are also detected between the ortho-hydrogen atom of isoquinoline and the adjacent $\mathrm{N}$ atom of the indazole fragments, forming $\mathrm{H}(1) \cdots \mathrm{N}(6)$ and $\mathrm{H}(21) \cdots \mathrm{N}(3)$ dual hydrogen bonds, which are further support-

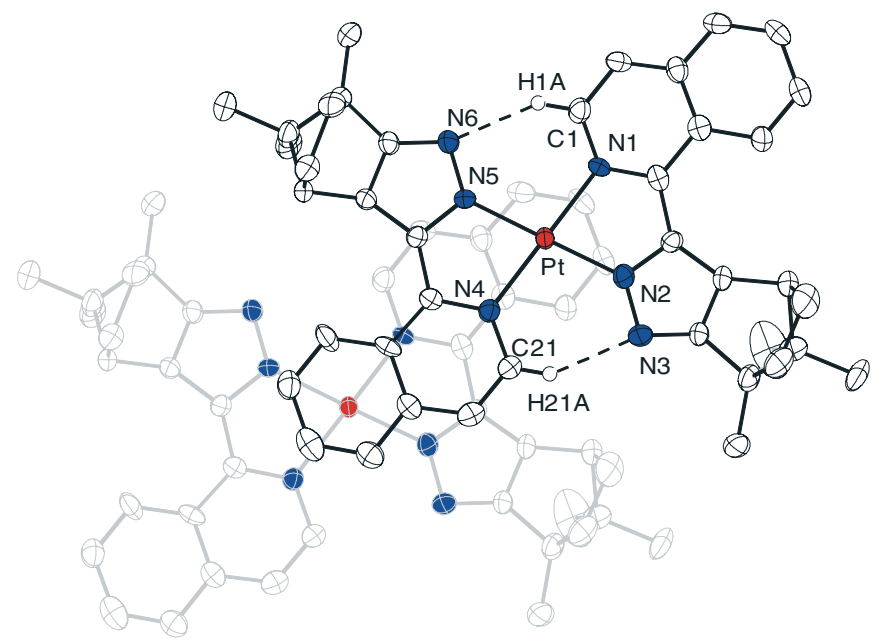

Figure 1. ORTEP diagram of 1 ; selected bond distances: $\mathrm{Pt}-\mathrm{N}(1)=$ $2.011(8), \quad \mathrm{Pt}-\mathrm{N}(2)=1.976(9), \quad \mathrm{Pt}-\mathrm{N}(4)=2.047(10), \quad \mathrm{Pt}-\mathrm{N}(5)=2.005(8)$, $\mathrm{H}(1) \cdots \mathrm{N}(6)=2.21, \mathrm{H}(21) \cdots \mathrm{N}(3)=2.21 \AA$ and angles: $\mathrm{N}(1)-\mathrm{Pt}-\mathrm{N}(2)=$ $78.0(4)^{\circ}, \mathrm{N}(4)-\mathrm{Pt}-\mathrm{N}(5)=78.3(3)^{\circ}$.

ed by the observation of an unusual downfield ${ }^{1} \mathrm{H}$ NMR chemical shift of $\delta 10.93$. The proposed intramolecular H-bonding interactions are reminiscent of those reported for pyridyl pyrazolate Os complexes as well as cobaloxime complexes. ${ }^{[0]}$ It is believed that this unusual H-bonding pattern, to a certain extent, provides a strong driving force to stabilize the observed trans-geometry. In contrast to our discovery, the X-ray structural analyses of related $\mathrm{Pt}^{\mathrm{II}}$ complexes such as $\mathrm{Pt}(\text { thppy })_{2}$, where thppy is 2-(2'-thienyl) pyridine, revealed that ligated thiophene and pyridine fragments are oriented exclusively in a cis-configuration, despite the large distortion and deformation of square planar geometry that occurred at the junction of the ligands. ${ }^{[1]}$ This could be due to the exceedingly strong trans-effect exerted by the carbon donor atom of the ligated thiophene.

\subsection{Photophysical Measurements}

As shown in Figure 2, although the energy gaps are quite different, similar spectral features are observed for complexes 1 and $\mathbf{2}$, consisting of a weak, broad band located in the longwavelength region, accompanied by a vibronic progression feature in the short-wavelength region that is commonly assigned to the singlet $\pi-\pi^{*}$ intra-ligand transitions ( $\left.{ }^{1} \mathrm{IL}\right)$. The low-frequency absorption bands have a relatively small extinction coefficient (1: $5240 \mathrm{M}^{-1} \mathrm{~cm}^{-1}$ at $502 \mathrm{~nm}$; : $4690 \mathrm{M}^{-1} \mathrm{~cm}^{-1}$ at $457 \mathrm{~nm})$ and are tentatively assigned to the transition incorporating a state mixing between singlet and triplet metalligand charge transfer $\left({ }^{1} \mathrm{MLCT}\right.$ and $\left.{ }^{3} \mathrm{MLCT}\right)$ and, to a certain extent, the intra-ligand triplet state $\left({ }^{3} \mathrm{IL}\right)$. Support for this viewpoint is first provided by a distinct shoulder at $530 \mathrm{~nm}$ $\left(\varepsilon \sim 4080 \mathrm{M}^{-1} \mathrm{~cm}^{-1}\right)$ resolved in the absorption spectrum of complex 1, which can be tentatively assigned to the lowest lying ${ }^{3}$ MLCT band (see below). The close energetics and absorptivity between the ${ }^{1}$ MLCT and ${ }^{3}$ MLCT bands suggest that the ${ }^{3}$ MLCT transition, induced by spin-orbit coupling and the 


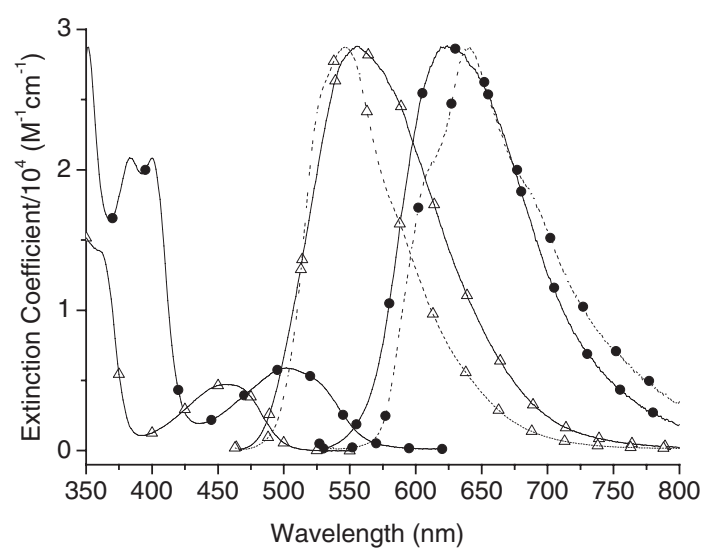

Figure 2. UV-vis absorption and emission spectra of $1\left(2.68 \times 10^{-5} \mathrm{M}\right.$, filled circles joined by solid lines) and $2\left(2.14 \times 10^{-5} \mathrm{M}\right.$, triangles joined by solid lines) in $\mathrm{CH}_{2} \mathrm{Cl}_{2}$ at RT. Note that the normalized emission spectra were acquired under degassed conditions. The dotted lines denote the corresponding solid-state emission obtained from a thin-film sample at RT.

proximal energy levels with respect to ${ }^{1} \mathrm{MLCT}$, is greatly enhanced and becomes partially allowed. This novel spectral feature is in accord with data for other recently published $\mathrm{Pt}^{\mathrm{II}}$ complexes bearing bis(phenoxy)diimine auxiliaries capable of tetradentate bonding. ${ }^{[12]}$ Although we have not explicitly examined and discussed the details of the singlet-triplet mixing, its presence is unambiguously confirmed by the obvious overlap between this UV-vis absorption band and the leading edge of the corresponding emission profile.

As for complex 2, the ${ }^{1}$ MLCT and ${ }^{3}$ MLCT states are so close that an asymmetric band was observed rather than the well-resolved dual absorption profile. Complex 1 exhibits an intensive emission with a maximum at $635 \mathrm{~nm}$ (quantum yield $\Phi=0.81$; lifetime $\tau=5.34 \mu \mathrm{s}$ ) in degassed $\mathrm{CH}_{2} \mathrm{Cl}_{2}$. The oxygen quenching rate of $1.78 \times 10^{9} \mathrm{M}^{-1} \mathrm{~s}^{-1}$ for the emission in $\mathrm{CH}_{2} \mathrm{Cl}_{2}$, in combination with its spectral mirror image with respect to the lowest absorption profile, leads us to conclude that the emission mainly originates from a triplet manifold. Similarly, complex 2 also exhibits strong phosphorescence with a peak wavelength at $553 \mathrm{~nm}(\Phi=$ $0.64 ; \tau=3.63 \mu \mathrm{s})$, which is comparable to those observed in the cyclometalated dipyridylbenzene Pt complexes. ${ }^{[13]}$ The observed radiative lifetimes for $\mathbf{1}$ and $\mathbf{2}$ in $\mathrm{CH}_{2} \mathrm{Cl}_{2}$ are relatively long for a pure ${ }^{3} \mathrm{MLCT}$ emission from complexes incorporating a central heavy atom like $\mathrm{Pt}^{\mathrm{II}}$ and a ${ }^{1}$ MLCT state in proximity. Accordingly, we tentatively propose that there exists, in part, a further state mixing with the ${ }^{3}$ IL manifold ${ }^{[14]}$ Firm support for this viewpoint is given by the unusually broad, structureless emission feature, with a full width at half maximum (FWHM) of $108 \mathrm{~nm}$ and $109 \mathrm{~nm}$ for $\mathbf{1}$ and $\mathbf{2}$, respectively, in $\mathrm{CH}_{2} \mathrm{Cl}_{2}$ at room temperature (RT), while upon cooling to $77 \mathrm{~K}$ the emission reveals distinctive vibroniclike features with peak wavelengths at 580, 614 (520), 656 (552), and 698 (596) $\mathrm{nm}$ for complex 1 (2) (see Fig. 3 and Table 1). Although not well resolved, similar structural features were also observed for both complexes in the solid state at RT (see Fig. 2). The spectral progression of $>1000 \mathrm{~cm}^{-1}$ for each successive peak cannot be rationalized by the much smaller d-level splitting in a square planar coordination, but is akin to that corresponding to the vibrational modes (1270$1300 \mathrm{~cm}^{-1}$ ) of aromatic terpyridyl ligands. ${ }^{[15]}$ Alternatively, it may be plausible that the broad FWHM, together with the vibronic structure features in a $77 \mathrm{~K} \mathrm{CH}_{2} \mathrm{Cl}_{2}$ solution as well as in the solid state at RT, arises from a state mixing between ${ }^{3}$ MLCT and ${ }^{3}$ IL. ${ }^{[16]}$ In a central planar configuration such as $\mathbf{1}$ and 2, the strong mixing of these two transitions essentially requires covalent interaction of the relevant d-orbitals and the ligand $\pi$-system, in which MLCT $\left[\mathrm{d}_{x z, y z} \rightarrow \pi^{*}\right]$ transitions should be the most likely candidates. ${ }^{[17]}$

Due to the planar geometry of the central $\mathrm{Pt}^{\mathrm{II}}$ atom possessing a dsp ${ }^{2}$ configuration, one has to consider the possible stacking effects for both $\mathbf{1}$ and $\mathbf{2}$. We thus carried out a concentration-dependent absorption/emission study in an attempt to resolve this issue. Upon varying the sample concentrations from $3.45 \times 10^{-5} \mathrm{M}$ to $1.07 \times 10^{-3} \mathrm{M}$, both absorption and emission spectra remain unchanged for $\mathbf{1}$ and $\mathbf{2}$, indicating that the stacking effect, if any, is too small to affect any associated photophysical behavior. It is thus reasonable to conclude that the introduction of a bulky camphor-derived group on the indazole fragment drastically increases the steric hindrance and hence suppresses aggregation. Supplementary support for this viewpoint is provided by the solid-state emission spectra in that both complexes (1: $\lambda_{\mathrm{em}}=638 \mathrm{~nm} ; \mathbf{2}: \lambda_{\mathrm{em}}=550 \mathrm{~nm}$, see Fig. 2$)$

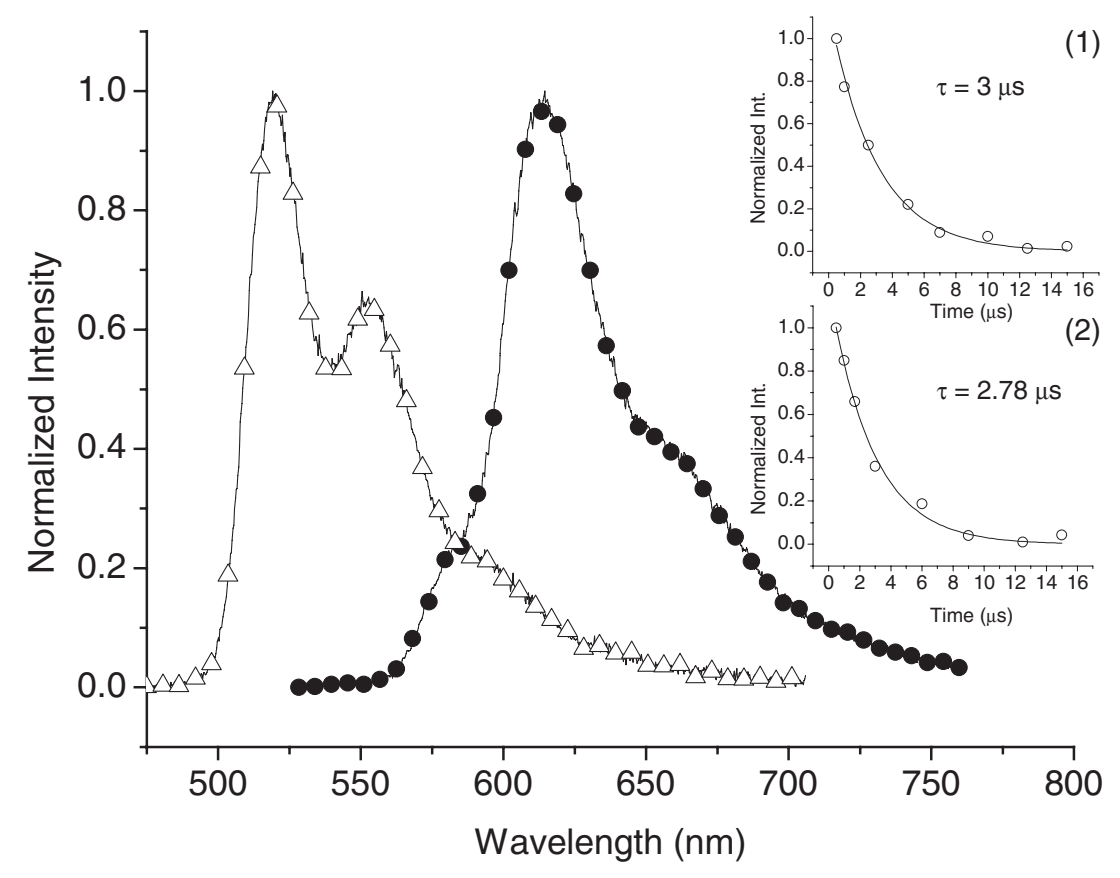

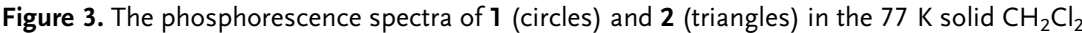
matrices. Insets: The phosphorescence decay profiles of complexes $\mathbf{1}$ and $\mathbf{2}$. 
Table 1. Photophysical properties of complexes $\mathbf{1}$ and $\mathbf{2}$ in degassed $\mathrm{CH}_{2} \mathrm{Cl}_{2}$ at RT.

\begin{tabular}{lllll}
\hline & $\lambda_{\mathrm{abs}}^{\max }\left[\varepsilon, \mathrm{M}^{-1} \mathrm{~cm}^{-1}\right]$ & $\mathrm{PL} \lambda_{\max }[\mathrm{nm}]$ & $\Phi$ & $\tau[\mu \mathrm{s}]$ \\
\hline $\mathrm{Pt}(\mathrm{iqdz})_{2}(1)$ & $502(5240)$ & 635 & 0.81 & 5.34 \\
& & $(610,638,688)[\mathrm{a}]$ & $0.20[\mathrm{a}]$ & $1.10[\mathrm{a}, \mathrm{c}]$ \\
& & $(580,614,656,698)[\mathrm{b}]$ & & $3.0[\mathrm{~b}]$ \\
$\mathrm{Pt}(\mathrm{pydz})_{2}$ (2) & $457(4690)$ & 553 & 0.64 & 3.63 \\
& & $(528,550,581)[\mathrm{a}]$ & $0.15[\mathrm{a}]$ & $3.38[\mathrm{a}, \mathrm{c}]$ \\
& & $(520,552,596)[\mathrm{b}]$ & & $2.78[\mathrm{~b}]$ \\
\hline
\end{tabular}

[a] The solid-state emission obtained from a thin-film sample at RT. [b] The phosphorescent emission recorded in frozen $\mathrm{CH}_{2} \mathrm{Cl}_{2}$ matrices at $77 \mathrm{~K}$. [c] Lifetime is an average value from a two-component fit.

manifest negligible spectral shifts from the corresponding emission maximum in solution, providing unambiguous evidence for the negligible stacking interaction in both complexes. It is noted that the solid-film photoluminescence (PL) is narrower than the solution PL. In addition, the PL spectra in the solid film show a slight blue shift for $\mathbf{2}$ and red shift for $\mathbf{1}$ in comparison with their corresponding emission in solution. If the solid state of a complex lacks strong intermolecular interaction such as hydrogen bonding, $\pi$ stacking, etc., a slight blue shift and narrowing for the solid-film PL relative to that of the solution PL may be expected, and can be attributed to a "medium effect". For complex 2 in solution, the stronger interaction from the solvent (e.g., $\mathrm{CH}_{2} \mathrm{Cl}_{2}$ ) makes the emission broader, whereas, due to the lack of $\pi$ stacking, complex 2 is more or less frozen and inhibited from having a closer interaction with itself. In comparison, the additional fused benzene of isoquinoline in complex $\mathbf{1}$ introduces a weak but perhaps non-negligible $\pi$ interaction in the solid film, resulting in a slightly red-shifted emission. Nevertheless, from solution to solid, the shift of peak wavelength is rather small for $\mathbf{1}$, indicating that the intermolecular interaction cannot be large. This viewpoint can be supported from X-ray single-crystal analysis, in which a rather long $\mathrm{Pt}$...Pt distance has been resolved for $\mathbf{1}$ (see above).

Table 1 lists detailed spectroscopic and dynamics data for $\mathbf{1}$ and $\mathbf{2}$ in solution and for single crystals. Despite the much lower energy gap with respect to that of the pyridyl counterpart $\mathbf{2}$, significant enhancement of the luminescent quantum yield $(\Phi \sim 0.81)$ is observed in $\mathbf{1}$, accompanied by a longer lifetime $(5.34 \mu \mathrm{s})$ in degassed $\mathrm{CH}_{2} \mathrm{Cl}_{2}$. These results seem to contradict the energy-gap law, in which the theory pertaining to non-radiative decay concludes that the non-radiative deactivation should increase with decreasing energy gap of the transition. ${ }^{[18]}$ We thus tentatively propose that the remarkable but unusual luminescence behavior in complex $\mathbf{1}$ is due to the highly conjugated $\pi$ systems in indazole coupled with the nearby isoquinoline fragments. One possible strategy to suppress the active vibrational modes, such as ring stretching and bending of the acceptor ligand that commonly dominates the deactivation of the MLCT excited states, is to use a ligand with a rigid $\sigma$-framework. In addition, upon excitation, the electron occupation of the lowest $\pi^{*}$ acceptor orbital results in increases of the $\mathrm{C}-\mathrm{C}$ and $\mathrm{C}-\mathrm{N}$ bond distances, inducing non-radiative transition due to the loose bonding effect. ${ }^{[19]}$ Since the Franck-Condon factor for non-radiative transitions is qualitatively proportional to the square of the bonding displacement, ${ }^{[20]}$ enlarging the $\pi$ conjugation should reduce the distortion of the ligand framework due to the smaller changes in average distance between ground and excited states. Accordingly, the non-radiative decay rate in $\mathbf{1}$ is expected to be relatively small to compete with the red phosphorescence, giving rise to an exceptionally high emission quantum yield. For comparison, Nazeeruddin et al. have recently reported near unity quantum yields for blue, green, and yellow emission by meticulous selection of the ligand on the $\mathrm{Ir}^{\mathrm{III}}$ system for strong ligand field strength, which increased the energy gaps between triplet emitting states and the nearby deactivating metal centered (MC) level. ${ }^{[21]}$ Other factors leading to the high emission yield for $\mathbf{1}$ or $\mathbf{2}$ are also possible. These include a) $\mathrm{Pt}^{\mathrm{II}}$ metal ion intrinsically possessing a relatively large d-orbital splitting, b) isoquinolinyl indazole (or pyridyl indazole) with a fairly strong ligand field inducing a larger gap between the MC states and the lowest unoccupied molecular orbital (LUMO) of the ligands. and c) close-lying $\pi-\pi^{*}$ and MLCT states together with the heavy atom effect enhancing the spin-orbital coupling. A comprehensive understanding of the relaxation mechanisms might have to rely on future theoretical approaches, which we are currently exploring.

\subsection{OLED Fabrication}

Due to its high phosphorescence quantum efficiency in the red, multilayer devices of the configuration ITO/NPB $(40 \mathrm{~nm}) / \mathrm{CBP}: \mathbf{1} \quad(30 \mathrm{~nm}) / \mathrm{BCP} \quad(10 \mathrm{~nm}) / \mathrm{Alq}_{3} \quad(30 \mathrm{~nm}) / \mathrm{LiF}$ $(1 \mathrm{~nm}) / \mathrm{Al}(150 \mathrm{~nm})$ were prepared, with doping concentrations of 1 varying from $6 \%, 12 \%, 20 \%, 50 \%$ to a neat film. Very bright red emission was observed for all the concentrations prepared, including the one with a pure layer of the platinum complex. The current-voltage $(I-V)$ curves, plotted in Figure 4, show a trend of increasing current density with increasing concentration of $\mathbf{1}$. The results may imply that the phosphorescent sites serve as charge trapping sites. The electroluminescence (EL) spectra originated only from the com-

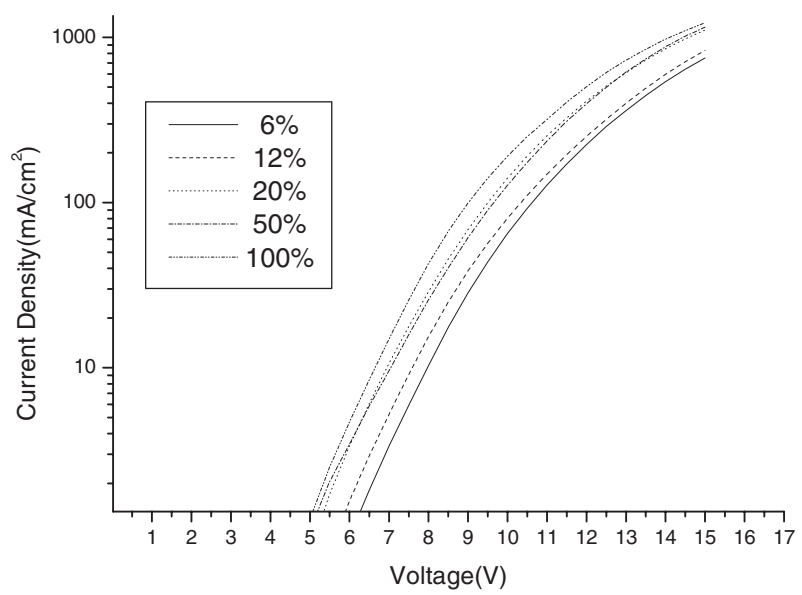

Figure 4. $I-V$ characteristics of OLED devices based on complex 1 for various dopant concentrations. 
plex in all cases, but with a small red shift of the EL spectra $\lambda_{\max }$ with increasing dopant concentration from $610 \mathrm{~nm}$ for the $6 \%$ dopant concentration to $630 \mathrm{~nm}$ for the neat film (Fig. 5). The FWHM of the EL spectrum also increased slightly (from $76 \mathrm{~nm}$ to $92 \mathrm{~nm}$ ) over the same range of doping concentrations. Comparing Figures 2 and 5, the EL from the device is slightly blue shifted from PL of the solid film. One possible origin for the shift is from the microcavity effect, which is caused by the interference between the forward-traveling light and the light reflected from the metal electrode. ${ }^{[22]}$

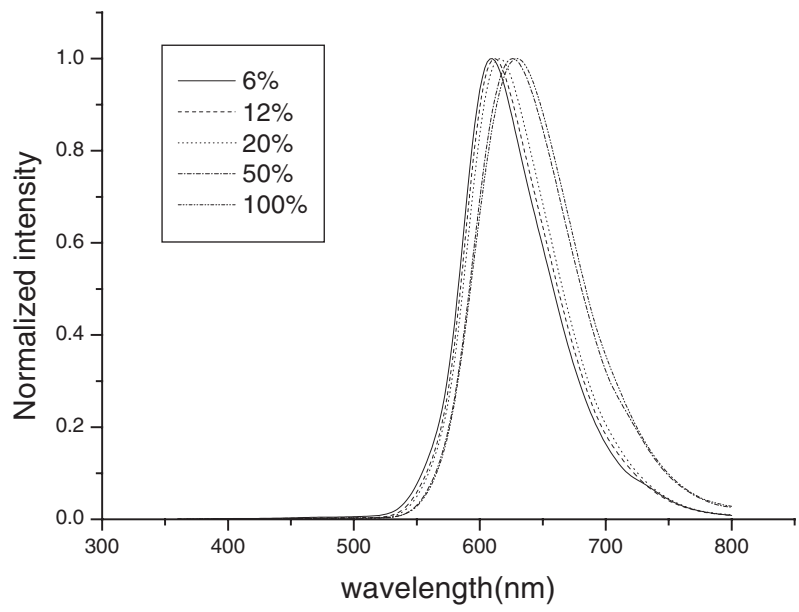

Figure 5. Electroluminescence spectra of OLED devices based on complex 1 for various dopant concentrations.

All devices showed a turn-on voltage as low as $4.0 \mathrm{~V}$. Although the devices still exhibited a similar dropping trend with increasing current (Fig. 6), as is the case for most phosphorescence-based devices, the performance characteristics are nevertheless very encouraging. For the device doped with $12 \% \mathbf{1}$ driven at a current of $100 \mathrm{~mA}$, a brightness of $10677 \mathrm{~cd} / \mathrm{m}^{2}$ was achieved with an external quantum efficiency of $\sim 7 \%$, a luminance efficiency of $\sim 11 \mathrm{~cd} / \mathrm{A}$ and a power efficiency of

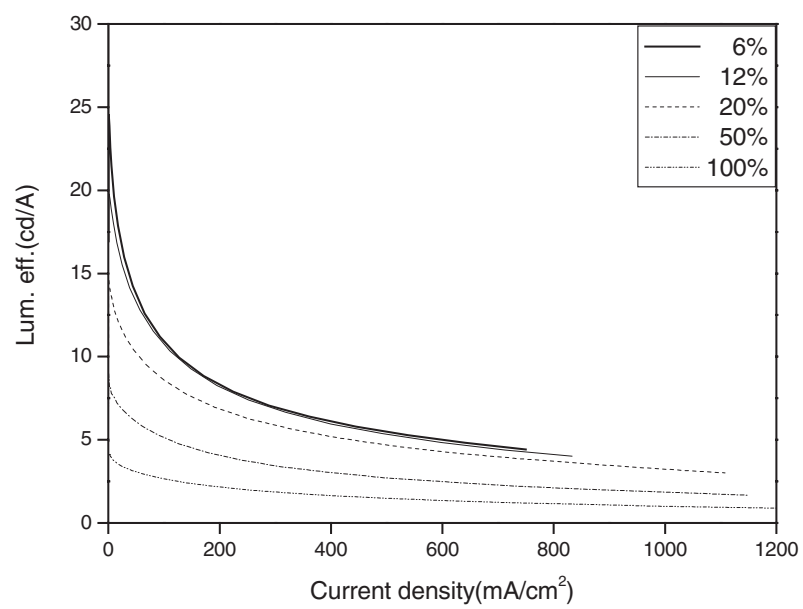

Figure 6. Luminance efficiencies of OLED devices based on complex 1 as a function of current density for various dopant concentrations.
$3.3 \mathrm{~lm} / \mathrm{W}$. The results also exhibited a decreasing trend with increasing concentration of the platinum dopant. However, it is noteworthy that, even using a pure film of $\mathbf{1}$ as the emission layer, a brightness of $2653 \mathrm{~cd} / \mathrm{m}^{2}$ and an external quantum efficiency of $2.46 \%$, luminance efficiency of $2.65 \mathrm{~cd} / \mathrm{A}$ and power efficiency of $0.93 \mathrm{~lm} / \mathrm{W}$ can be achieved. The relatively high efficiency of the device even in the neat complex is tentatively attributed to the unusually short radiative lifetime that avoids the triplet-triplet annihilation. Table 2 summarizes the performance data for various concentrations studied. The achievement of high luminescence efficiency can be attributed to a much shorter phosphorescence radiative lifetime in combination with a rationally designed structure that greatly suppresses the aggregation effect. It should be noted that rigid steric blockers such as a pinene functionality incorporated into an octahedral phenyl pyridine Ir $^{\mathrm{III}}$ complex ${ }^{[23]}$ have been reported to effectively reduce self-quenching of the phosphorescent dopant. While improving the device luminescence efficiency, this prior innovation based on $\operatorname{Ir}(\mathrm{ppy})_{3}$ and its pinene-derivatized complexes exhibits green emission rather than the muchneeded saturated red emission.

\section{Conclusion}

In summary, we report detailed syntheses and luminescence properties of red-light- (1) and green-light- (2) emitting $\mathrm{Pt}^{\mathrm{Il}}$ metal complexes using a bulky ligand incorporating a camphor-derived moiety. These complexes exhibit high emission quantum yields, short phosphorescence radiative lifetimes in the range of several microseconds and, more importantly, a much lower tendency to aggregation than previously reported $\mathrm{Pt}^{\mathrm{II}}$ porphyrinato or $\beta$-diketonato complexes for electroluminescent applications. ${ }^{[2]}$ Remarkable improvement of the device performance has been achieved at higher dopant concentrations or even in a pure emission layer, constituting for the first time a highly efficient $\mathrm{Pt}^{\mathrm{II}}$-based OLED in the red.

\section{Experimental}

General Procedures: All reactions were performed under nitrogen Solvents were distilled from appropriate drying agents prior to use Commercially available reagents were used without further purification unless otherwise stated. All reactions were monitored by thinlayer chromatography (TLC) with Merck pre-coated glass plates $\left(0.20 \mathrm{~mm}\right.$ with fluorescent indicator $\left.\mathrm{UV}_{254}\right)$. Compounds were visualized with UV light irradiation at $254 \mathrm{~nm}$ and $365 \mathrm{~nm}$. Flash column chromatography was carried out using silica gel from Merck (230-400 mesh). Mass spectra were obtained on a JEOL SX-102A instrument operating in electron impact (EI) or fast atom bombardment (FAB) mode. ${ }^{1} \mathrm{H}$ and ${ }^{13} \mathrm{C}$ NMR spectra were recorded on a Bruker-400 or INOVA-500 instrument; chemical shifts are quoted with respect to the internal standard tetramethylsilane for ${ }^{1} \mathrm{H}$ and ${ }^{13} \mathrm{C}$ NMR data. Elemental analysis was carried out with a Heraeus $\mathrm{CHN}-\mathrm{O}$ Rapid Elementary Analyzer.

Spectroscopic and Dynamic Measurements: Steady-state absorption and emission spectra were recorded on a Hitachi (U-3310) spectrophotometer and an Edinburgh (FS920) fluorimeter, respectively. Both wavelength-dependent excitation and emission response of the fluorimeter were calibrated. A configuration of front-face excitation was used to measure the emission of the solid sample, in which the cell was made 
Table 2. Performance characteristics for the electrophosphorescence devices based on complex $\mathbf{1}$.

\begin{tabular}{|c|c|c|c|c|c|c|c|c|}
\hline $\begin{array}{l}\text { Doping } \\
\text { conc. [\%] }\end{array}$ & $\begin{array}{l}\text { Brightness } \\
{\left[\mathrm{cd} / \mathrm{m}^{2}\right]}\end{array}$ & $\begin{array}{l}\eta_{\text {ext }} \\
{[\%]}\end{array}$ & $\begin{array}{l}\text { Lum. eff. } \\
{[\mathrm{cd} / \mathrm{A}]}\end{array}$ & $\begin{array}{l}\text { Power eff. } \\
{[\mathrm{lm} / \mathrm{W}]}\end{array}$ & $\begin{array}{l}V_{\text {drive }} \\
{[\mathrm{V}]}\end{array}$ & $\begin{array}{l}V_{\text {turn-on }} \\
{[\mathrm{V}]}\end{array}$ & $\begin{array}{l}\text { FWHM } \\
\lambda_{\max }[\mathrm{nm}]\end{array}$ & $\operatorname{CIE}(x, y)$ \\
\hline \multirow[t]{3}{*}{6} & 3451 [a] & 10.6 & 17.43 & 6.37 & 8.61 & 4 & $610 / 76$ & $0.61,0.38$ \\
\hline & 10846 [b] & 6.6 & 10.92 & 3.24 & 10.61 & & & \\
\hline & $33193(15)$ [c] & $14.9(5.5)$ & $24.57(5.5)$ & $14.86(5.0)$ & & & & \\
\hline \multirow[t]{3}{*}{12} & 3210 [a] & 10.51 & 16.21 & 6.20 & 8.24 & 3.8 & $612 / 78$ & $0.62,0.37$ \\
\hline & 10677 [b] & 6.98 & 10.76 & 3.28 & 10.32 & & & \\
\hline & $33394(15)[c]$ & $12.8(6.0)$ & $19.79(6.0)$ & $12.43(4.5)$ & & & & \\
\hline \multirow[t]{3}{*}{20} & 2378 [a] & 8.28 & 11.97 & 4.95 & 7.6 & 3.5 & $616 / 80$ & $0.63,0.37$ \\
\hline & 8592 [b] & 5.95 & 8.59 & 2.84 & 9.5 & & & \\
\hline & $33454(15)[c]$ & $10.2(5.0)$ & $14.7(5.0)$ & $9.28(4.5)$ & & & & \\
\hline \multirow[t]{3}{*}{50} & 1397 [a] & 6.23 & 7.04 & 2.87 & 7.71 & 3.6 & $626 / 88$ & $0.64,0.36$ \\
\hline & 5101 [b] & 4.55 & 5.14 & 1.68 & 9.63 & & & \\
\hline & $19430(15)[c]$ & $8.00(4.5)$ & $9.03(4.5)$ & $6.31(4.5)$ & & & & \\
\hline \multirow[t]{3}{*}{100} & $694[a]$ & 3.24 & 3.5 & 1.52 & 7.23 & 3.8 & $630 / 92$ & $0.64,0.35$ \\
\hline & 2653 [b] & 2.46 & 2.65 & 0.93 & 9.01 & & & \\
\hline & $10733(15)$ [c] & $3.91(4.5)$ & $4.22(4.5)$ & $2.95(4.5)$ & & & & \\
\hline
\end{tabular}

[a] Values collected at $20 \mathrm{~mA} / \mathrm{cm}^{2}$. [b] Values collected at $100 \mathrm{~mA} / \mathrm{cm}^{2}$. [c] Maximum values of the devices. Values in parentheses are the voltages at which they were obtained.

by assembling two edge-polished quartz plates with various Teflon spacers. A combination of appropriate filters was used to avoid interference from the scattering light. Lifetime studies were performed by an Edinburgh FL 900 photon-counting system with a hydrogen-filled lamp or a nitrogen lamp as the excitation source. Data were analyzed using a nonlinear least squares procedure in combination with an iterative convolution method. The emission decays were analyzed by the sum of exponential functions, which allows partial removal of the instrument time broadening and consequently renders a temporal resolution of $\sim 200$ ps.

To determine the photoluminescence quantum yield in solution, samples were degassed by three freeze-pump-thaw cycles under vigorous stirring conditions. 4-(Dicyanomethylene)-2-methyl-6-(p-dimethylaminostyryl)- $4 H$-pyran (DCM, $\lambda_{\mathrm{em}}=615 \mathrm{~nm}$, Exciton, Inc.) in methanol was used as a reference, assuming a quantum yield of 0.43 with $430 \mathrm{~nm}$ excitation [24]. An integrating sphere (Labsphere) was applied to measure the quantum yield in the solid state, in which the solid-sample film was prepared via either spin-coating or vapor-deposition methods and was excited by a $514 \mathrm{~nm}$ (complex 1) or $457 \mathrm{~nm}$ (complex 2) $\mathrm{Ar}^{+}$laser line. The resulting luminescence was led to an intensified charge-coupled detector for subsequent quantum yield analyses. To obtain the PL quantum yield in the solid state, the emission was collected via an integrating sphere, and the quantum yield was calculated according to a reported method [25].

Synthesis of 4,8,8-Trimethyl-3-isoquinoline-1-yl-4,5,6,7-tetrahydro2H-4,7-methano-indazole, (iqdz)H: To a stirred mixture of $\mathrm{NaH}$ $(0.26 \mathrm{~g}, 10.8 \mathrm{mmol})$ and tetrahydrofuran (THF, $10 \mathrm{~mL})$ at $0{ }^{\circ} \mathrm{C}$ was added a solution of $(1 R)-(+)$-camphor $(1.64 \mathrm{~g}, 10.8 \mathrm{mmol})$ in THF for a period of $10 \mathrm{~min}$. The temperature of the reaction mixture was slowly increased to RT and stirring was continued for about $30 \mathrm{~min}$. Then the solution was heated to $60^{\circ} \mathrm{C}$, and ethyl 1-isoquinolinecarboxylate $(1.7 \mathrm{~g}, 8.5 \mathrm{mmol})$ in THF was added slowly and refluxed for about $3 \mathrm{~h}$. After this period, the reaction mixture was cooled to $0{ }^{\circ} \mathrm{C}$ and quenched with dilute $\mathrm{HCl}$ to $\mathrm{pH} 8-9$. Then it was extracted with ethyl acetate $(2 \times$ $100 \mathrm{~mL}$ ), and the extracts were washed with brine and water, dried over anhydrous $\mathrm{MgSO}_{4}$ and concentrated in vacuo to give a yellow oil $(2.2 \mathrm{~g})$. Hydrazine monohydrate $(4.2 \mathrm{~mL}, 86.0 \mathrm{mmol})$ in $\mathrm{EtOH}$ was added dropwise to a refluxing solution of the above oil $(2.2 \mathrm{~g})$, without further purification, in EtOH $(30 \mathrm{~mL})$. After the mixture was refluxed for $12 \mathrm{~h}$, the solvent was removed under vacuum. The residue obtained was dissolved in ethyl acetate and washed with water, dried over anhydrous $\mathrm{MgSO}_{4}$, and concentrated again. The residue obtained was passed through a silica gel column using mixtures of hexane and ethyl acetate as eluents to give (iqdz) $\mathrm{H}$ as colorless crystals $(1.4 \mathrm{~g}, 55 \%)$.

Spectral Data: MS (EI), m/z 303, M+. ${ }^{1} \mathrm{H}$ NMR $\left(500 \mathrm{MHz}, \mathrm{CDCl}_{3}\right.$, $294 \mathrm{~K}): \delta[\mathrm{ppm}] 8.51(\mathrm{~d}, J=5.8 \mathrm{~Hz}, 1 \mathrm{H}), 8.42(\mathrm{~d}, J=8.3 \mathrm{~Hz}, 1 \mathrm{H}), 7.81$ $(\mathrm{d}, J=8.4 \mathrm{~Hz}, 1 \mathrm{H}), 7.67$ (ddd, $J=8.3,6.8,1.3 \mathrm{~Hz}, 1 \mathrm{H}), 7.61$ (ddd, $J=$
$8.4,6.8,1.5 \mathrm{~Hz}, 1 \mathrm{H}), 7.56(\mathrm{~d}, J=5.8 \mathrm{~Hz}$ $1 \mathrm{H}), 3.00(\mathrm{~d}, J=4.0 \mathrm{~Hz}, 1 \mathrm{H}), 2.19(\mathrm{~m}, 1 \mathrm{H})$, $1.92(\mathrm{~m}, 1 \mathrm{H}), 1.44(\mathrm{~m}, 2 \mathrm{H}), 1.35(\mathrm{~s}, 3 \mathrm{H})$ $0.98 \quad(\mathrm{~s}, 3 \mathrm{H}), 0.79 \quad(\mathrm{~s}, 3 \mathrm{H}) \cdot{ }^{13} \mathrm{C} \quad \mathrm{NMR}$ $\left(125 \mathrm{MHz}, \mathrm{CDCl}_{3}, 294 \mathrm{~K}\right): \delta[\mathrm{ppm}] 167.1$ $149.9,141.8,136.8,132.5,130.2,127.3$, 127.0, 126.3, 126.2, 125.5, 120.1, 61.0, 50.4, 50.0, 33.6, 27.5, 20.5, 19.2, 10.6. Anal. Calcd. for $\mathrm{C}_{20} \mathrm{H}_{21} \mathrm{~N}_{3}$ : C 79.17, $\mathrm{H}$ 6.98, N 13.85 . Found: C 79.49, H 6.98, N 13.92.

Synthesis of Pt(iqdz) $)_{2}(\mathbf{1})$ : A solution of potassium tetrachloroplatinate $\left(\mathrm{K}_{2} \mathrm{PtCl}_{4}\right)$ $(0.1 \mathrm{~g}, \quad 0.24 \mathrm{mmol}), \quad($ iqdz $) \mathrm{H} \quad(0.16 \mathrm{~g}$, $0.53 \mathrm{mmol})$ in a mixture of ethanol $(15 \mathrm{~mL})$ and water $(5 \mathrm{~mL})$ was heated at $80^{\circ} \mathrm{C}$ for about $16 \mathrm{~h}$. After this period, the reaction mixture was cooled and the precipitated solid was filtered off, washed with ether, and dried under vacuum to give $\mathrm{Pt}(\mathrm{iqdz})_{2}$ as a red solid (1, $0.15 \mathrm{~g}, 78 \%$ ). Crystals of $\mathbf{1}$ suitable for X-ray analysis were obtained by recrystallization from a mixture of dichloromethane and hexane at room temperature.

Spectral Data of 1: MS (FAB), $m / z$ 800, $\mathrm{M}^{+} .{ }^{1} \mathrm{H}$ NMR $(400 \mathrm{MHz}$, $\left.\mathrm{CD}_{2} \mathrm{Cl}_{2}, 294 \mathrm{~K}\right): \delta[\mathrm{ppm}] 10.93(\mathrm{~d}, J=6.4 \mathrm{~Hz}, 2 \mathrm{H}), 8.86(\mathrm{~d}, J=8.2 \mathrm{~Hz}$, $2 \mathrm{H}), 7.94(\mathrm{~d}, J=7.8 \mathrm{~Hz}, 2 \mathrm{H}), 7.86(\mathrm{dd}, J=8.2,7.0 \mathrm{~Hz}, 2 \mathrm{H}), 7.76(\mathrm{dd}, J$ $=7.8,7.0 \mathrm{~Hz}, 2 \mathrm{H}), 7.63(\mathrm{~d}, J=6.4 \mathrm{~Hz}, 2 \mathrm{H}), 3.44(\mathrm{~d}, J=2.8 \mathrm{~Hz}, 2 \mathrm{H})$, $2.34(\mathrm{~m}, 2 \mathrm{H}), 2.02(\mathrm{~m}, 2 \mathrm{H}), 1.58-1.47(\mathrm{~m}, 4 \mathrm{H}), 1.52(\mathrm{~s}, 6 \mathrm{H}), 1.09(\mathrm{~s}, 6 \mathrm{H})$ $0.85(\mathrm{~s}, 6 \mathrm{H}) .{ }^{13} \mathrm{C}$ NMR $\left(100 \mathrm{MHz}, \mathrm{CD}_{2} \mathrm{Cl}_{2}, 294 \mathrm{~K}\right): \delta[\mathrm{ppm}] 164.8$ $156.5,144.2,142.1,136.9,132.1,128.2,127.8,127.6,126.9,123.8,118.4$ 60.8, 52.8, 50.7, 34.1, 27.9, 20.5, 19.4, 10.9. Anal. Calcd. for $\mathrm{C}_{40} \mathrm{H}_{40} \mathrm{~N}_{6} \mathrm{Pt}$ : C 60.43, H 5.32, N 10.31. Found: C 60.52, H 5.29, N 10.58 .

Synthesis of 4,8,8-Trimethyl-3-pyridin-2-yl-4,5,6,7-tetrahydro-2H-4,7methano-indazole, $(p y d z) H$ : Using the same conditions as for (iqdz) $\mathrm{H}$, starting from ethyl picolinate and $(1 R)-(+)$-camphor, the title compound was obtained as white crystals (yield $34 \%$ ).

Spectral Data: MS (EI), $m / z$ 253, $\mathrm{M}^{+} .{ }^{1} \mathrm{H}$ NMR $\left(500 \mathrm{MHz}, \mathrm{CDCl}_{3}\right.$, $294 \mathrm{~K}): \delta[\mathrm{ppm}] 8.58(\mathrm{~d}, J=5.5 \mathrm{~Hz}, 1 \mathrm{H}), 7.69(\mathrm{ddd}, J=7.8,7.5,1.8,7.53$ $(\mathrm{d}, J=7.8 \mathrm{~Hz}, 1 \mathrm{H}), 7.15(\mathrm{ddd}, J=7.5,5.5,1.3 \mathrm{~Hz}, 1 \mathrm{H}), 3.03(\mathrm{~d}, J=$ $4.5 \mathrm{~Hz}, 1 \mathrm{H}), 2.14(\mathrm{~m}, 1 \mathrm{H}), 1.87(\mathrm{~m}, 1 \mathrm{H}), 1.35(\mathrm{~m}, 1 \mathrm{H}), 1.24(\mathrm{~m}, 1 \mathrm{H}) 1.31$ (s, 3H), 0.98 (s, 3H), 0.71 (s, 3H). ${ }^{13} \mathrm{C}$ NMR $\left(125 \mathrm{MHz}, \mathrm{CDCl}_{3}, 294 \mathrm{~K}\right)$ : $\delta[\mathrm{ppm}] 167.6,149.2,149.1,136.9,133.5,124.6,122.1,120.5,61.2,50.3$, 48.2, 33.5, 27.2, 20.5, 19.3, 10.5. Anal. Calcd. for $\mathrm{C}_{16} \mathrm{H}_{19} \mathrm{~N}_{3}$ : C 75.85, $\mathrm{H}$ 7.56, N 16.59. Found: C 76.07, H 7.48, N 16.60

Synthesis of Pt(pydz) $)_{2}(\mathbf{2})$ : Using the same conditions as for $\mathrm{Pt}(\mathrm{iqdz})_{2}$ (1), starting from $\mathrm{K}_{2} \mathrm{PtCl}_{4}$ and the ligand (pydz) $\mathrm{H}$, the title compound 2 was obtained as a yellow powder (yield $50 \%$ ).

Spectral Data of 2: MS (FAB), m/z 700, $\mathrm{M}^{+} .{ }^{1} \mathrm{H}$ NMR $(500 \mathrm{MHz}$ $\left.\mathrm{CDCl}_{3}, 294 \mathrm{~K}\right): \delta[\mathrm{ppm}] 10.72(\mathrm{brs}, 2 \mathrm{H}), 7.82(\mathrm{dd}, J=7.5,7.5 \mathrm{~Hz}, 2 \mathrm{H})$ $7.52(\mathrm{~d}, J=8.0 \mathrm{~Hz}, 2 \mathrm{H}), 7.22(\mathrm{brs}, 2 \mathrm{H}), 3.03(\mathrm{~d}, J=4.0 \mathrm{~Hz}, 2 \mathrm{H}), 2.13$ $(\mathrm{m}, 2 \mathrm{H}), 1.86(\mathrm{~m}, 2 \mathrm{H}), 1.35-1.44(\mathrm{~m}, 2 \mathrm{H}), 1.19(\mathrm{~m}, 2 \mathrm{H}), 1.42(\mathrm{~s}, 6 \mathrm{H})$ $0.97(\mathrm{~s}, 6 \mathrm{H}), 0.78(\mathrm{~s}, 6 \mathrm{H}) .{ }^{13} \mathrm{C}$ NMR $\left(125 \mathrm{MHz}, \mathrm{CDCl}_{3}, 294 \mathrm{~K}\right): \delta[\mathrm{ppm}]$ $164.5,155.0,152.8,142.5,138.7,126.1,120.9,118.2,61.8,50.9,47.9,33.8$ 27.8, 20.8, 19.7, 11.2. Anal. Calcd. for $\mathrm{C}_{32} \mathrm{H}_{36} \mathrm{~N}_{6} \mathrm{Pt}$ : C 54.93, H 5.19, N 12.01. Found: C 54.85, H 5.22, N 11.91.

$X$-Ray Structural Analysis: Single-crystal X-ray diffraction data were measured on a Bruker Smart charge-coupled device (CCD) diffractometer using (Mo K) radiation $(\lambda=0.71073 \AA)$. The data collection was executed using the SMART program. Cell refinement and data reduction were carried out with the SAINT program. The structure was determined using the SHELXTL/PC program and refined using fullmatrix least squares. All non-hydrogen atoms were refined anisotropically, whereas hydrogen atoms were placed at the calculated positions and included in the final stage of refinements with fixed parameters.

Selected Crystal Data of 1: $\mathrm{C}_{40} \mathrm{H}_{40} \mathrm{~N}_{6} \mathrm{Pt}, \mathrm{M}=799.87$, monoclinic, space group $P 2{ }_{1} / \mathrm{n}, a=6.8567(3), b=18.4625(9), c=15.5327(8) \AA, \beta=$ 95.824(1) $)^{\circ}, V=1956.6(16) \AA^{3}, Z=2, \rho \rho_{\text {calcd }}=1.358 \mathrm{mg} \mathrm{m}^{-3}, F(000)=$ 800 , crystal size $=0.40 \mathrm{~mm} \times 0.10 \mathrm{~mm} \times 0.03 \mathrm{~mm}, \lambda(\mathrm{Mo} \mathrm{K \alpha})=$ $0.7107 \AA, T=295(2) \mathrm{K}, \mu=3.620 \mathrm{~mm}^{-1}, 18030$ reflections collected $\left(R_{\text {int }}=0.0467\right)$, final $R_{l}[I>2 \sigma(I)]=0.0573$ and $w R_{2}($ all data $)=0.1552$. 
The crystallographic data of this complex (excluding structure factors) have been deposited at the Cambridge Crystallographic Data Centre with the deposition number CCDC-238230. The data can be obtained free of charge on application to CCDC, 12 Union Road, Cambridge CB2 1EZ, UK (fax: (+44) 1223336 033; e-mail: deposit@ccdc.cam.ac.uk).

OLED Fabrication: Charge transporting materials such as NPB $\left\{4,4^{\prime}\right.$-bis[ $N$-(1-naphthyl)- $N$-phenylamino]biphenyl $\}$ and $\mathrm{Alq}_{3}$ [tris $(8$-hydroxyquinolinato)aluminium(III)], as well as the host material CBP $\left(4,4^{\prime}-N, N^{\prime}\right.$-dicarbazolyl-1,1'-biphenyl) were synthesized according to literature procedures [26], and were sublimed twice through a temperature-gradient sublimation system before use. BCP (2,9-dimethyl-4,7-diphenyl-1,10-phenanthroline) was obtained from Aldrich. Patterned ITO-coated glass substrates (sheet resistance $\leq 30 \Omega / \square$ ) with an effective individual device area of $3.14 \mathrm{~mm}^{2}$ were cleaned by sonication in a detergent solution, water, and ethanol, separately, and then dried by a flow of nitrogen. The substrates were further treated with oxygen plasma for 3 min before being loaded into the vacuum chamber. Various organic layers were deposited sequentially at a rate of $0.1-0.3 \mathrm{~nm} / \mathrm{s} \mathrm{un}-$ der a pressure of $2 \times 10^{-5}$ torr in an Ulvac Cryogenic deposition system. Phosphorescent dopants were co-evaporated with CBP via two independent sources. A thin layer of $\operatorname{LiF}(1 \mathrm{~nm})$ and a thick layer of $\mathrm{Al}$ $(150 \mathrm{~nm})$ followed as the cathode. The current-voltage-luminance of the devices was measured in ambient conditions with a Keithley 2400 Source meter and a Newport $1835 \mathrm{C}$ Optical meter equipped with an 818ST silicon photodiode. The EL spectrum was obtained using a Hitachi F4500 spectrofluorimeter. The active area of the device was $3.14 \mathrm{~mm}^{2}$ and that of the silicon photodiode was $100 \mathrm{~mm}^{2}$. The device was placed close to the photodiode such that all the forward light went to the photodiode. The external quantum efficiency was calculated according to the method described before [27]. The luminous flux [ $[\mathrm{m}]$ is defined [28] by

$P_{\mathrm{v}}=K_{\mathrm{m}} \int_{\lambda} P_{\mathrm{e}, \lambda} V(\lambda) \mathrm{d} \lambda$

where $K_{\mathrm{m}}$ is the maximum luminous efficiency $(683 \mathrm{~lm} / \mathrm{W}), P_{\mathrm{e}, \lambda}$ is the spectral concentration of radiant flux, $V(\lambda)$ is the relative photopic luminous efficiency function; the luminance $\left[\mathrm{cd} / \mathrm{m}^{2}\right]$ is defined by $P_{\mathrm{v}} / \pi a$, where $a$ is the device area; the luminous efficiency [cd/A] is defined by $P_{\mathrm{v}} / \pi I$, where $I$ is the current; power efficiency is defined as $P_{\mathrm{v}} / I V$, where $V$ is the applied voltage.

Received: March 29, 2004 Final version: April 28, 2004

[1] a) M. A. Baldo, D. F. O'Brien, Y. You, A. Shoustikov, S. Sibley, M. E. Thompson, S. R. Forrest, Nature 1998, 395, 151. b) S. Lamansky, R. C. Kwong, M. Nugent, P. I. Djurovich, M. E. Thompson, Org. Electron. 2001, 2, 53. c) X. Gong, M. R. Robinson, J. C. Ostrowski, D. Moses, G. C. Bazan, A. J. Heeger, Adv. Mater. 2002, 14, 581 .

[2] a) R. C. Kwong, S. Sibley, T. Dubovoy, M. Baldo, S. R. Forrest, M. E. Thompson, Chem. Mater. 1999, 11, 3709. b) C.-M. Che, Y.-J. Hou, M. C. W. Chan, J. Guo, Y. Liu, Y. Wang, J. Mater. Chem. 2003, 13, 1362

[3] a) B. Carlson, G. D. Phelan, W. Kaminsky, L. Dalton, X. Z. Jiang, S. Liu, A. K.-Y. Jen, J. Am. Chem. Soc. 2002, 124, 14162. b) S. Bernhard, X. Gao, G. G. Malliaras, H. D. Abruna, Adv. Mater. 2002, 14, 433; c) J. H. Kim, M. S. Liu, A. K.-Y. Jen, B. Carlson, L. R. Dalton, C.-F. Shu, R. Dodda, Appl. Phys. Lett. 2003, 83, 776.

[4] a) S. Lamansky, P. Djurovich, D. Murphy, F. Abdel-Razzaq, H.-E. Lee, C. Adachi, P. E. Burrows, S. R. Forrest, M. E. Thompson, J. Am. Chem. Soc. 2001, 123, 4304. b) A. Tsuboyama, H. Iwawaki, M. Furugori, T. Mukaide, J. Kamatani, S. Igawa, T. Moriyama, S. Miura, T. Takiguchi, S. Okada, M. Hoshino, K. Ueno, J. Am. Chem. Soc. 2003, 125, 12971.

[5] a) K. E. Dungey, B. D. Thompson, N. A. P. Kane-Maguire, L. L. Wright, Inorg. Chem. 2000, 39, 5192. b) S.-C. Chan, M. C. W. Chan, Y. Wang, C.-M. Che, K.-K. Cheung, N. Zhu, Chem. Eur. J. 2001, 7, 4180. c) Y.-Y. Lin, S.-C. Chan, M. C. W. Chan, Y.-J. Hou, N. Zhu, C.-M. Che, Y. Liu, Y. Wang, Chem. Eur. J. 2003, 9, 1263.
[6] a) C. N. Pettijohn, E. B. Jochnowitz, B. Chuong, J. K. Nagle, A. Vogler, Coord. Chem. Rev. 1998, 171, 85. b) W. B. Connick, D. Geiger, R. Eisenberg, Inorg. Chem. 1999, 38, 3264. c) M. Hissler, J. E. McGarrah, W. B. Connick, D. K. Geiger, S. D. Cummings, R. Eisenberg, Coord. Chem. Rev. 2000, 208, 115.

[7] The synthetic methodology is somewhat related to those reported for the analogous (2-pyridyl) pyrazole ligands. See a) P.-C. Wu, J.-K. Yu, Y.-H. Song, Y. Chi, P.-T. Chou, S.-M. Peng, G.-H. Lee, Organometallics 2003, 22, 4938. b) C.-C. Cheng, W.-S. Yu, P.-T. Chou, S.-M. Peng, G.-H. Lee, P.-C. Wu, Y.-H. Song, Y. Chi, Chem. Commun. 2003, 2628.

[8] a) L. Chassot, E. Müller, A. Von Zelewsky, Inorg. Chem. 1984, 23, 4249. b) M. Ghedini, D. Pucci, A. Crispini, G. Barberio, Organometallics 1999, 18, 2116.

[9] a) V. M. Miskowski, V. H. Houlding, C. M. Che, Y. Wang, Inorg. Chem. 1993, 32, 2518. b) T. J. Wadas, R. J. Lachicotte, R. Eisenberg, Inorg. Chem. 2003, 42, 3772.

[10] B. D. Gupta, V. Singh, R. Yamuna, T. Barclay, W. Cordes, Organometallics 2003, 22, 2670.

[11] M. Gianini, A. Forster, P. Haag, A. von Zelewsky, H. Stoeckli-Evans, Inorg. Chem. 1996, 35, 4889

[12] Y.-Y. Lin, S.-C. Chan, M. C. W. Chan, Y.-J. Hou, N. Zhu, C.-M. Che, Y. Liu, Y. Wang, Chem. Eur. J. 2003, 9, 1263.

[13] J. A. G. Williams, A. Beeby, E. S. Davies, J. A. Weinstein, C. Wilson, Inorg. Chem. 2003, 42, 8609 .

[14] a) L. Sacksteder, A. P. Zipp, E. A. Brown, J. Streich, J. N. Demas, B. A. DeGraff, Inorg. Chem. 1990, 29, 4335. b) L. Sacksteder, M. Lee, J. N. Demas, B. A. DeGraff, J. Am. Chem. Soc. 1993, 115, 8230.

[15] a) Q.-Z. Yang, L.-Z. Wu, Z.-X. Wu, L.-P. Zhang, C.-H. Tung, Inorg. Chem. 2002, 41, 5653. b) V. W.-W. Yam, R. P.-L. Tang, K. M.-C. Wong, K.-K. Cheung, Organometallics 2001, 20, 4476.

[16] a) J. DePriest, G. Y. Zheng, N. Goswami, D. M. Eichhorn, C. Woods, D. P. Rillema, Inorg. Chem. 2000, 39, 1955. b) G. Y. Zheng, D. P. Rillema, J. DePriest, C. Woods, Inorg. Chem. 1998, 37, 3588. c) G. Y. Zheng, D. P. Rillema, Inorg. Chem. 1998, 37, 1392.

[17] W. B. Connick, V. M. Miskowski, V. H. Houlding, H. B. Gray, Inorg. Chem. 2000, 39, 2585.

[18] a) S. R. Johnson, T. D. Westmoreland, J. V. Caspar, K. R. Barqawi, T. J. Meyer, Inorg. Chem. 1988, 27, 3195. b) C. E. Whittle, J. A. Weinstein, M. W. George, K. S. Schanze, Inorg. Chem. 2001, 40, 4053.

[19] a) J. V. Caspar, T. D. Westmoreland, G. H. Allen, P. G. Bradley, T. J. Meyer, W. H. Woodruff, J. Am. Chem. Soc. 1984, 106, 3492. b) E. M. Kober, T. J. Meyer, Inorg. Chem. 1985, 24, 106.

[20] a) A. El-Ghayoury, A. Harriman, A. Khatyr, R. Ziessel, Angew. Chem., Int. Ed. 2000, 39, 185. b) P. A. Anderson, F. R. Keene, T. J. Meyer, J. A. Moss, G. F. Strouse, J. A. Treadway, J. Chem. Soc. Dalton Trans. 2002, 3820. c) Y.-Q. Fang, N. J. Taylor, G. S. Hanan, F. Loiseau, R. Passalacqua, S. Campagna, H. Nierengarten, A. Van Dorsselaer, J. Am. Chem. Soc. 2002, 124, 7912 .

[21] M. K. Nazeeruddin, R. Humphry-Baker, D. Berner, S. Rivier, L. Zuppiroli, M. Grätzel, J. Am. Chem. Soc. 2003, 125, 8790.

[22] a) A. Dodabalapur, L. J. Rothberg, T. M. Miller, E. W. Kwock, Appl. Phys. Lett. 1994, 64, 2486. b) S. K. So, W. K. Choi, L. M. Leung, K. Neyts, Appl. Phys. Lett. 1999, 74, 1939. c) Y. Fukuda, T. Watanabe, T. Wakimoto, S. Miyaguchi, M. Tsuchida, Synth. Met. 2000, 111-112, 1.

[23] H. Z. Xie, M. W. Liu, O. Y. Wang, X. H. Zhang, C. S. Lee, L. S. Hung, S. T. Lee, P. F. Teng, H. L. Kwong, H. Zheng, C. M. Che, Adv. Mater. 2001, 13, 1245.

[24] J. M. Drake, M. L. Lesiecki, D. M. Camaioni, Chem. Phys. Lett. 1985 , 113,530 .

[25] J. C. de Mello, H. F. Wittmann, R. H. Friend, Adv. Mater. 1997, 9, 230

[26] a) A. Y. Sonsale, S. Gopinathan, C. Gopinathan, Indian J. Chem. 1976, 14, 408. b) B. E. Koene, D. E. Loy, M. E. Thompson, Chem. Mater. 1998, 10, 2235.

[27] S. R. Forrest, D. D. C. Bradley, M. E. Thompson, Adv. Mater. 2003 , $15,1043$.

[28] G. Wyszecki, W. S. Stiles, Color Science: Concepts and Methods, Quantitative Data and Formulae, Wiley, New York 1982, p. 259. 